\title{
KDR inferred haplotype is associated with upper limb dysfunction in breast cancer survivors of mixed ancestry
}

This article was published in the following Dove Press journal: Cancer Management and Research

\author{
Trevor S Mafu' \\ Alison V September ${ }^{\prime}$ \\ Delva Shamley ${ }^{2}$ \\ 'Division of Exercise Science and Sports \\ Medicine, Department of Human Biology, \\ Faculty of Health Sciences, University of \\ Cape Town, Cape Town, South Africa; \\ ${ }^{2}$ Clinical Research Centre, Faculty of \\ Health Sciences, University of Cape \\ Town, Rondebosch, South Africa
}

Introduction: Shoulder pain and disability are well-documented sequelae of breast cancer treatment. Angiogenesis signaling may have a role in the development of shoulder pain or shoulder disability in breast cancer survivors. The aim of this study was to determine if polymorphisms in angiogenesis-related genes are associated with shoulder pain or disability following breast cancer treatment.

Participants and methods: A cross-sectional study was conducted on 220 South African breast cancer survivors. The study aimed to evaluate associations between shoulder pain/ disability and seven single nucleotide polymorphisms (SNPs) within five angiogenesisassociated genes: KDR (rs2305948 C>T; rs7667298 C>T), NOS3 (rs1549758 C > T), MMP2 (rs708269 A>T), THBS2 (rs9766678 A>G) and TIMP3 (rs5754312 T>A; rs715572 G>A). In addition, associations between shoulder pain/disability and inferred haplotypes for $K D R$ and TIMP3 SNPs were evaluated. Participants were grouped into no-low and moderate-high shoulder pain/disability based on total pain/disability scores: $\leq 30$ and $>30$, respectively using the shoulder pain and disability index (SPADI).

Results: No independent associations with shoulder pain/disability categories were found for all SNPs. However, 1 inferred haplotype (KDR "TT") differed significantly $(P=0.014)$ between the shoulder disability categories. After adjusting for participants' age, the differences in KDR inferred haplotype frequencies between shoulder disability categories became non-significant $(P=0.052)$.

Conclusion: Our findings provide a preliminary suggestion of a possible association between polymorphisms in genes involved in angiogenesis and the presence of moderatehigh shoulder disability among South African breast cancer survivors. A larger prospective cohort study is currently being conducted by our group.

Keywords: angiogenesis, shoulder pain, polymorphism, breast cancer therapy

\section{Introduction}

Shoulder pain and disability are well-known consequences of conventional breast cancer treatment. $^{1-7}$ Such morbidities may persist long after the recovery period for breast cancer treatment ${ }^{3,4,7}$ and have been associated with reduced quality of life. ${ }^{1,8,9}$ Prevalence rates of up to $68 \%$ have been reported for shoulder pain or disability beyond 6 months after primary treatment although they vary widely. ${ }^{3-6,10,11}$ The complex etiology of breast cancer treatment-related shoulder pain and disability has long been appreciated and several risk factors have been identified including: treatment type, time after treatment, disease characteristics, age, genetic factors and the presence of co-
Correspondence: Delva Shamley Clinical Research Centre, Faculty of Health Sciences, University of Cape Town, Anzio Rd, Observatory, Cape Town 7925, South Africa

Email Delva.shamley@uct.ac.za 
morbidities. $^{2,6,12,13}$ However, a large proportion of variability in the development of morbidity after breast cancer treatment still remains unexplained. ${ }^{12,14}$ Previous findings suggest that shoulder morbidity after breast cancer treatment is bilateral $^{2,10,15}$ and it has been shown that structures unrelated to direct surgery and/or radiotherapy treatment are affected, ${ }^{16}$ suggesting a systemic cause. These findings substantiate the need to explore the potential involvement of molecular signaling pathways.

Several molecular signaling pathways have been implicated in non-cancer shoulder complex morbidity including but not limited to angiogenesis, extracellular matrix (ECM) remodeling and apoptosis. ${ }^{17-25}$ Such studies, investigating the role of molecular pathways, included connective tissue conditions of the shoulder such as tendon injuries or tendinopathy and rotator cuff disease (RCD). ${ }^{26}$ Angiogenesis appears to be particularly important in shoulder complex morbidity in healing and adaption pathways. Its signaling can induce ECM remodeling and nitric oxide synthase (NOS) activity. ${ }^{27,28}$ NOS activity has been shown to be upregulated in rotator cuff tendon injury and may play a role in the healing process. ${ }^{29-31}$ Hypoxia-inducible factor $1 \alpha$ (HIF-1 $\alpha)$, a pro-angiogenic transcription factor, is elevated in rotator cuff pathology (including impingement, tendinopathy or tears). ${ }^{25}$ Although non-cancer shoulder conditions have a different etiology, the altered shoulder movement patterns observed in breast cancer survivors mimic those seen in known general shoulder conditions such as rotator cuff disease and adhesive capsulitis. ${ }^{7}$ In fact, such diagnoses have been used to describe shoulder-complex morbidities in breast cancer survivors and have strongly been associated with pain. ${ }^{32-34}$ Studies evaluating the role of molecular signaling pathways in breast cancer treatmentrelated morbidity have largely focused on the inflammatory pathway. ${ }^{26}$ Evaluation of signaling factors involved in angiogenesis, ECM remodeling or apoptosis in breast cancer survivors may, therefore, increase our understanding of the pathophysiology, and contribute towards an explanation of the individual variability in the development, of shoulder pain and disability.

There is a lack of relevant studies investigating the role of angiogenesis, ECM remodeling and NOS activity in the development of shoulder pain and disability after breast cancer treatment. Previous studies evaluating gene expression profiles or genetic associations, in the context of morbidity following breast cancer treatment, have largely focused on inflammatory factors with a few exceptions. ${ }^{26}$ Such studies did not focus, specifically, on shoulder pain/disability as a clinical end-point.
${ }^{26}$ ECM remodeling and NOS activity are important events in angiogenesis signaling. Angiogenesis signaling through KDR (Kinase Insert Domain Receptor), its main signaling receptor, activates ECM remodeling factors such as MMPs (matrix metalloproteinases), and eNOS (endothelial NOS). ${ }^{35,36}$ The activity of KDR can be regulated by inhibitors such as thrombospondins (THBSs) while the activity of MMPs can be regulated by TIMPs (tissue inhibitor of MMPs). ${ }^{37,38}$ We hypothesize that shoulder pain or disability after breast cancer treatment may be associated with polymorphisms in genes involved in angiogenesis, ECM remodeling or NOS activity. The aim of this study, therefore, was to correlate DNA sequence variants of key angiogenesis-related signaling factors, including genes involved in ECM remodeling and NOS activity: KDR, MMP2, NOS3, THBS2, TIMP3, with the occurrence of shoulder pain or shoulder disability among female breast cancer survivors.

\section{Methods}

\section{Study design}

This is a pilot, cross-sectional study including a genetic association component. This study is a sub-study of a larger on-going project which seeks to correlate clinical disease state of the shoulder after breast cancer treatment with biomarkers of inflammation, fibrosis and angiogenesis, including their associated genetic variants.

\section{Participants and setting}

Study participants were recruited in the period August 2013 to July 2015, and relevant information regarding the study was provided upon recruitment. Participants, all women, were conveniently recruited from the waiting room of the Oncology Clinic of a tertiary public teaching hospital in South Africa. Although women of all races were recruited, only the larger "mixed-ancestry" ethnic group (Mixed-ancestry group: $n=243$, Black: $n=43$, White: $n=22$ ) was used for analysis to avoid confounding. The mixed-ancestry ethnic group, from the Western Cape region of South Africa, used in our study is composed of populations who self-identify as "Coloured." This is a unique group with a rich genetic admixture ancestrally derived from immigrants from Western Europe, West Africa, Asia and the indigenous Southern African populations. All participants agreeing to participate gave written informed consent and were included on the basis of defined inclusion and exclusion criteria (Table 1). 
Table I Inclusion and exclusion criteria for participant recruitment

\begin{tabular}{|c|c|}
\hline $\begin{array}{l}\text { Inclusion } \\
\text { criteria }\end{array}$ & Exclusion criteria \\
\hline $\begin{array}{l}\text { - }>18 \text { years old } \\
\text { - Females } \\
\text { - Unilateral } \\
\text { breast cancer } \\
\text { - } \geq 1 \text { year after } \\
\text { surgery } \\
\text { - Mixed- } \\
\text { ancestry }\end{array}$ & $\begin{array}{l}\text { - History of shoulder or neck pathology prior to } \\
\text { treatment for breast cancer } \\
\text { - Diagnoses of connective tissue disorders such } \\
\text { as rheumatoid arthritis or systemic lupus } \\
\text { erythematosus } \\
\text { - Diagnoses of renal insufficiency, diabetes melli- } \\
\text { tus or hyper-cholesterolemia } \\
\text { - Diagnosed local recurrence } \\
\text { - Diagnosed lymphoedema }\end{array}$ \\
\hline
\end{tabular}

\section{Study procedures}

The study was approved by the Human Research and Ethics Committee at the University of Cape Town (HREC REF: 650/2016). After providing informed consent, eligible participants completed the Shoulder Pain and Disability Index (SPADI) questionnaire and blood were drawn by venepuncture on the cubital fossa of the unaffected side. For each participant, $10 \mathrm{~mL}$ of blood was collected into appropriately labeled EDTA vacutainer blood collection tubes. Whole blood samples were immediately stored at $-20{ }^{\circ} \mathrm{C}$ until total DNA extraction. DNA was extracted from whole blood using the method described by Lahiri et al $(1991)^{39}$ and stored at $-20{ }^{\circ} \mathrm{C}$. Out of 244 eligible participants, blood and/or DNA of sufficient quality (non-degraded) was available from 220 participants (90.2\%). All relevant clinical variables for each participant including age, self-reported race, date of surgery, tumor grade, type of surgery, lymph node surgery, number of nodes removed and adjuvant therapy type were obtained from participants' medical records.

\section{Patient-reported outcome: SPADI}

Participants completed the Shoulder Pain and Disability Index (SPADI) questionnaire - a Patient Report Outcome Measure with 2 domains: Pain and Disability. $^{40,41}$ Using the SPADI, participants rated movement-related pain and difficulty associated with specific activities of daily living on a scale of 0 (no pain/difficulty) - 10 (extreme pain/difficulty). The pain subscale of the SPADI has 5 items whereas the disability subscale has 8 items. However, both scales are reported as percentages of possible total scores. For each subscale, the total score was divided by the number of completed items and expressed as a percentage.

\section{Variables of interest}

The primary outcome measure in this study was the shoulder pain and disability index (SPADI). Pain and disability scores were categorized into no - low pain/disability and moderatehigh pain/disability based on total pain or disability scores $\leq 30$ and $>30$, respectively. The development of these categories was based on reported SPADI score effects on activities of daily living ${ }^{42}$ and reported clinical relevance of SPADI scores. ${ }^{40}$ Exposures in this study are bi-allelic SNP genotypes from 5 candidate genes: $K D R$ (VEGF-R2) (rs2305948 C>T; rs7667298 C $>\mathrm{T}$ ), NOS3 (rs1549758 $\mathrm{C}>\mathrm{T})$, MMP2 (rs708269 A>T), THBS2 (rs9766678 A>G) and TIMP3 (rs5754312 T>A; rs715572 G>A). Potential covariates evaluated for association included participants' age at consent, time after surgery, type of surgery, extent of lymph node surgery, number of lymph nodes removed, tumor grade and adjuvant therapy type.

\section{Single nucleotide polymorphism selection}

SNPs within genes involved in the angiogenesis signaling pathway were selected for analysis. The selection of SNPs was based on functional significance or being located in important gene regions, having a reported global minor allele frequency $>0.15$ in the ENSEMBL database ([http:// www.ensembl.org]), and/or previous associations with multifactorial conditions of the shoulder, as well as musculoskeletal soft tissue injuries in general. A total of seven SNPs from five genes were included (Tables 2 and 3). In order to ensure robust genetic association analyses, only SNP call rates of $>95 \%$ and Hardy-Weinberg $P$-values of $>0.05$ were included.

\section{Genotype determination}

Genotyping was performed using TaqMan ${ }^{\mathrm{TM}}$ assays (Applied Biosystems) in 96-well plates with adherence to manufacturer's instructions in a StepOnePlus (Applied Biosystems) real-time PCR System at UCT Department of Human Biology. The reaction mix was as follows: Allele-specific TaqMan ${ }^{\mathrm{TM}}$ primer and probe $\operatorname{mix}-0.15 \mu \mathrm{L}$, DNA template $-1 \mu \mathrm{L}(1-10 \mathrm{ng}), \mathrm{H}_{2} \mathrm{O}-$ $2.85 \mu \mathrm{L}$, and TaqMan $^{\mathrm{TM}}$ PCR mastermix containing ampliTaq DNA polymerase Gold $-4 \mu \mathrm{L}$; Final reaction volume of $8 \mu \mathrm{L}$. Both negative (no DNA sample) and positive (DNA of known genotypes) controls were included in every plate as a quality control measure for reliability of the PCR and for the detection of potential genotyping errors. In addition, replicates 
Table 2 Differences in demographic and clinical characteristics between shoulder pain categories

\begin{tabular}{|c|c|c|c|c|}
\hline Characteristic & $\begin{array}{l}\text { No-low } \\
\text { pain }(n=184)\end{array}$ & $\begin{array}{l}\text { Moderate-high pain } \\
(n=60)\end{array}$ & P-value & Test \\
\hline $\begin{array}{l}\text { Age (years) } \\
\text { Time after surgery } \\
\text { (years) } \\
\text { Nodes removed } \\
\text { Total pain score } \\
\text { Total disability score }\end{array}$ & $\begin{array}{l}59.7 \pm 8.8 \\
3.7 \pm 2.4 \\
10.7 \pm 6.3 \\
8.3 \pm 9.0 \\
3.7 \pm 7.4\end{array}$ & $\begin{array}{l}54.3 \pm 10.6 \\
3.4 \pm 2.5 \\
9.2 \pm 5.4 \\
55.5 \pm 18.6 \\
37.7 \pm 21.6\end{array}$ & $\begin{array}{l}<0.001 \\
0.372 \\
0.105 \\
<0.001 \\
<0.001\end{array}$ & $\begin{array}{l}\text { Independent sample } t \text {-test (by group/ } \\
\text { category) }\end{array}$ \\
\hline $\begin{array}{l}\text { Side of primary } \\
\text { Left } \\
\text { Right }\end{array}$ & $\begin{array}{l}51.1(93) \\
48.9(89)\end{array}$ & $\begin{array}{l}55.0(33) \\
45.0(27)\end{array}$ & 0.656 & $F$ \\
\hline $\begin{array}{l}\text { Tumor grade } \\
\text { III } \\
\text { II } \\
\text { I }\end{array}$ & $\begin{array}{l}23.9(39) \\
52.8(86) \\
23.3(38)\end{array}$ & $\begin{array}{l}21.8(12) \\
50.9(28) \\
27.3(15)\end{array}$ & 0.833 & $\chi^{2}$ \\
\hline $\begin{array}{l}\text { Type of surgery } \\
\text { Mastectomy } \\
\text { WLE }\end{array}$ & $\begin{array}{l}82.0(150) \\
18.0(33)\end{array}$ & $\begin{array}{l}71.2(42) \\
28.8(17)\end{array}$ & 0.095 & $F$ \\
\hline $\begin{array}{l}\text { Lymph node surgery } \\
\text { ALND } \\
\text { SLNB }\end{array}$ & $\begin{array}{l}85.3(156) \\
14.8(27)\end{array}$ & $\begin{array}{l}81.4(48) \\
18.6(11)\end{array}$ & 0.537 & $F$ \\
\hline $\begin{array}{l}\text { Chemotherapy } \\
\text { Yes } \\
\text { No }\end{array}$ & $\begin{array}{l}75.0(135) \\
25.0(45)\end{array}$ & $\begin{array}{l}85.0(5 \mathrm{I}) \\
15.0(9)\end{array}$ & 0.152 & $F$ \\
\hline $\begin{array}{l}\text { Hormonal therapy } \\
\text { Yes } \\
\text { No }\end{array}$ & $\begin{array}{l}77.0(134) \\
23.0(40)\end{array}$ & $\begin{array}{l}81.0(47) \\
19.0(11)\end{array}$ & 0.587 & $F$ \\
\hline $\begin{array}{l}\text { Hormonal regimen } \\
\text { None } \\
\text { Tamoxifen } \\
\text { Aromatase inhibitor } \\
\text { Both }\end{array}$ & $\begin{array}{l}23.3(40) \\
60.5(104) \\
8.1(14) \\
8.1(14)\end{array}$ & $\begin{array}{l}19.0(11) \\
63.8(37) \\
5.1(3) \\
12.1(7)\end{array}$ & 0.639 & $\chi^{2}$ \\
\hline $\begin{array}{l}\text { Radiotherapy } \\
\text { Yes } \\
\text { No }\end{array}$ & $\begin{array}{l}67.4(116) \\
32.6(56)\end{array}$ & $\begin{array}{l}75.9(44) \\
24.1(14)\end{array}$ & 0.252 & $F$ \\
\hline
\end{tabular}

Notes: Data presented as mean \pm SD or \% (n). P-values in bold typeset indicate significance $(P<0.05)$.

Abbreviations: WLE, Wide local excision; ALND, Axillary lymph node dissection; SLNBM, Sentinel lymph node biopsy; $t, t$-test; $F$, Fisher's exact test; $\chi^{2}$, Chi-squared test.

were also included in every plate. Samples were considered successfully genotyped unless they failed twice to amplify for a particular SNP assay. More than $99 \%$ of all samples were successfully genotyped for each SNP (only 1 out of 220 samples were unsuccessfully genotyped for each of NOS3 rs1549758, MMP2 rs708269 and THBS2 rs9766678. Data generated from the assays were analyzed using Thermo Fisher Cloud genotyping analysis Software Version: 3.3.0-SR2-build 21 and genotypes were automatically called.

\section{inferred haplotype construction}

$K D R$ and TIMP 3 haplotype pairs were inferred using the genotypes at rs2305948 $\mathrm{C}>\mathrm{T}$ and $\mathrm{rs} 7667298 \mathrm{C}>\mathrm{T}$, and 
Table 3 Differences in demographic and clinical characteristics between shoulder disability categories

\begin{tabular}{|c|c|c|c|c|}
\hline Characteristic & $\begin{array}{l}\text { No - Low Disability } \\
(n=202)\end{array}$ & $\begin{array}{l}\text { Moderate - High Disability } \\
(n=42)\end{array}$ & $P$-value & Test \\
\hline Age (years) & $59.1 \pm 9.1$ & $55.2 \pm 10.9$ & 0.016 & \multirow{7}{*}{$\begin{array}{l}\text { Independent sample } t \text {-test (by } \\
\text { group/category) }\end{array}$} \\
\hline Time after surgery & $3.6 \pm 2.4$ & $3.4 \pm 2.3$ & 0.645 & \\
\hline (years) & & & & \\
\hline Nodes removed & $10.5 \pm 6.2$ & $9.4 \pm 5.2$ & 0.303 & \\
\hline Total pain score & $11.7 \pm 14.3$ & $58.9 \pm 20.5$ & $<0.001$ & \\
\hline Total disability score & $4.3 \pm 6.8$ & $49.5 \pm 15.2$ & $<0.001$ & \\
\hline Side of primary & & & \multirow{3}{*}{$0.50 \mathrm{I}$} & \\
\hline Left & $51.0(102)$ & $57.1(24)$ & & \multirow[t]{2}{*}{$\mathrm{F}$} \\
\hline Right & $49.0(98)$ & $42.9(18)$ & & \\
\hline Tumor grade & & & \multirow{4}{*}{0.584} & \multirow{4}{*}{$\chi^{2}$} \\
\hline III & $22.8(4 I)$ & $26.3(10)$ & & \\
\hline II & $53.9(97)$ & 44.7 (I7) & & \\
\hline 1 & $23.3(42)$ & $29.0(11)$ & & \\
\hline Type of surgery & & & \multirow{3}{*}{0.834} & \multirow{3}{*}{$\mathrm{F}$} \\
\hline Mastectomy & $79.6(160)$ & 78.1 (32) & & \\
\hline WLE & $20.4(4 I)$ & $22.0(9)$ & & \\
\hline $\begin{array}{l}\text { Lymph node } \\
\text { surgery }\end{array}$ & & & \multirow{3}{*}{0.482} & \multirow{3}{*}{$\mathrm{F}$} \\
\hline ALND & $85.1(|7|)$ & $80.5(33)$ & & \\
\hline SLNB & $14.9(30)$ & $19.5(8)$ & & \\
\hline Chemotherapy & & & \multirow{3}{*}{0.102} & \multirow{3}{*}{$\mathrm{F}$} \\
\hline Yes & 75.3 (I49) & 88.1 (37) & & \\
\hline No & $24.8(49)$ & $11.9(5)$ & & \\
\hline $\begin{array}{l}\text { Hormonal } \\
\text { therapy }\end{array}$ & & & \multirow{3}{*}{0.836} & \multirow{3}{*}{$\mathrm{F}$} \\
\hline Yes & 77.5 (148) & $80.5(33)$ & & \\
\hline No & $22.5(43)$ & $19.5(8)$ & & \\
\hline $\begin{array}{l}\text { Hormonal } \\
\text { regimen }\end{array}$ & & & \multirow{6}{*}{0.765} & \multirow{6}{*}{$\chi^{2}$} \\
\hline None & $22.8(43)$ & $19.5(8)$ & & \\
\hline Tamoxifen & $60.9(115)$ & $63.4(26)$ & & \\
\hline Aromatase & $7.9(15)$ & $4.9(2)$ & & \\
\hline inhibitor & & & & \\
\hline Both & $8.5(16)$ & $12.2(5)$ & & \\
\hline Radiotherapy & & & \multirow{3}{*}{1.000} & \multirow{3}{*}{$\mathrm{F}$} \\
\hline Yes & $69.6(133)$ & $69.2(27)$ & & \\
\hline No & $30.4(58)$ & $30.8(12)$ & & \\
\hline
\end{tabular}

Notes: Data presented as mean \pm SD or \% (n). P-values in bold typeset indicate statistical significance $(P<0.05)$.

Abbreviations: WLE, Wide local excision; ALND, Axillary lymph node dissection; SLNB, Sentinel lymph node biopsy; $t$, $t$-test; $F$, Fisher's exact test; $\chi^{2}$ Chi-squared test. 
rs715572 $\mathrm{G}>\mathrm{A}$ and $\mathrm{rs} 5754312 \mathrm{~T}>\mathrm{A}$, respectively. A low haplotype frequency cut-off of $4 \%$ was used to avoid unreliable results.

\section{Bias}

Just under $10 \%$ ( $n=23$, out of a total $n=243$ ) of participants could not provide bloodbecause they were lost after consent due to the need for further medical examination in the clinic. There could potentially be differences between participants who provided blood and those who did not. However, this is unlikely, as all participants approached consented.

\section{Sample size}

Assuming expected average baseline risks of $32 \%$ and $25 \%$ for shoulder pain and disability, respectively, calculated from previous reports, ${ }^{3,4,6,9,43-48}$ sample size of 220 is likely sufficient to detect odds ratios of 2.0 and greater, at $80 \%$ power for allele frequencies of $\geq 0.2$ for the log-additive genetic model (Table S2). For the same log-additive genetic model, our sample size is also sufficient to detect odds ratios of 2.5 for allele frequencies $\geq 0.15$ (Table S2). However, for the dominant genetic model, our sample size is only sufficient to detect odds ratios of 2.5 for allele frequencies $\geq 0.15$ (Table S2). Furthermore, our sample size is underpowered for the recessive genetic model for effect sizes of 1.5-2.5 odds ratios, and allele frequencies of $0.15-0.5$. Sample size was calculated using QUANTO version 1.2.4. ${ }^{49}$

\section{Statistical analysis}

Demographic and clinical data were analyzed using Statistica Version 13.2. ${ }^{50}$ Independent sample $t$-tests, Fisher's exact tests and Chi-square analyses were done to evaluate for differences in demographic and clinical characteristics between the shoulder pain and disability categories. Logistic regression analysis based on a generalized linear model was used to evaluate the magnitude and precision of the association between significant clinical or demographic characteristics in $\mathrm{R}$ version 3.3.3. ${ }^{51}$ The genotype data were analyzed using R Studio Version 1.0.136, running $\mathrm{R}$ version 3.3.3. ${ }^{51}$ Chi-squared and Fisher's exact tests were used to analyze any differences in the genotype, allele or haplotype frequencies between the clinical categories. HardyWeinberg equilibrium (HWE) and linkage disequilibrium (LD) was calculated using 'genetics' Version 1.3.8.1 package. ${ }^{52}$ Haplotypes were inferred using the $\mathrm{R}$ package haplo.stats. ${ }^{53,54}$ Logistic regression analyses were performed using SNPassoc Version 1.9-2 to evaluate the association between genotypic characteristics and pain and disability category membership. ${ }^{55}$ Significant covariates among clinical and demographic characteristics were included in the final multivariate regression analyses. The regression models were evaluated using package "modEvA" version 1.3.2 in R, using the Hosmer-Lemeshow goodness of fit test and $D^{22} .56$

\section{Results \\ Differences in clinical and demographic characteristics between pain/disability categories}

No significant differences $(P>0.05)$ were noted between the no-low and moderate-high shoulder pain categories for the number of nodes removed, side of primary cancer, tumour grade, type of surgery, extent of lymph node surgery and receipt of adjuvant chemotherapy, hormonal therapy (and hormonal regimen) or radiation therapy (Table 2). However, participants in the no-low shoulder pain category were significantly $(P<0.001)$ older $(59.7 \pm 8.8)$ compared with those in the moderate-high shoulder pain category $(54.3 \pm 10.6)$.

Similarly, no significant differences $(P>0.05)$ were noted between the no-low and moderate-high shoulder disability categories for the number of nodes removed, side of primary cancer, tumour grade, type of surgery, extent of lymph node surgery and receipt of adjuvant chemotherapy, hormonal therapy (and hormonal regimen) or radiation therapy (Table 3 ). However, participants in the no-low shoulder disability category were significantly $(P=0.016)$ older $(59.1 \pm 9.1)$ compared with those in the moderate-high disability category $(55.2 \pm 10.9)$.

No significant differences $(P>0.05)$ were noted between shoulder pain categories, and shoulder disability categories for radiotherapy field and adjuvant chemotherapy regimen (Tables $\mathrm{S} 1$ and $\mathrm{S} 2$ ).

\section{Logistic regression analyses for participants' age}

In the regression analysis of participants' age as a predictor for shoulder pain, the odds of being in the moderate-high shoulder pain category decreased significantly for older participants (OR 0.94, 95\% CI: 0.91,0.97; P<0.001) (Table 4). This means that older participants had lower odds, while younger participants had higher odds, of reporting moderate-high shoulder pain. The regression model predicted 5.2\% of the variance in shoulder pain category membership.

In the regression analysis of participants' age as a predictor for shoulder disability, the odds of being in the moderate-high shoulder disability category decreased 
Table 4 Logistic regression analysis for participants' age at consent to predict moderate-high shoulder pain

\begin{tabular}{|l|l|l|l|l|l|}
\hline Predictor & Odds ratio & Standard error & $\mathbf{9 5 \%} \mathbf{C l}$ & $\mathbf{Z}$ value & $P$-value \\
\hline Age & 0.94 & 0.016 & $0.91,0.97$ & -3.67 & $<0.001$ \\
\hline
\end{tabular}

Notes: Overall model fit: $\chi^{2}=9.83, P=0.043, D^{2}=0.052$. Cls $(95 \%)$ in the format: lower, upper. $P$-values in bold typeset indicate statistical significance $(P<0.05)$.

Table 5 Logistic regression analysis for participants' age at consent to predict moderate-high shoulder disability

\begin{tabular}{|l|l|l|l|l|l|}
\hline Predictor & Odds ratio & Standard error & $\mathbf{9 5 \%} \mathbf{C l}$ & $\mathbf{Z}$ value & $\boldsymbol{P}$-value \\
\hline Age & 0.96 & 0.018 & $0.93,0.99$ & -2.38 & $\mathbf{0 . 0 1 7}$ \\
\hline
\end{tabular}

Notes: Overall model fit: $\chi^{2}=5.18, P=0.075, \mathrm{D} 2=0.025$. Cis $(95 \%)$ in the format: lower, upper. $P$-values in bold typeset indicate statistical significance $(P<0.05)$.

significantly for older participants (OR $0.96,95 \%$ CI: $0.93,0.99 ; P=0.017$ ) (Table 5). This means that older participants had lower odds, while younger participants had higher odds of reporting moderate-high shoulder disability. The regression model predicted $2.5 \%$ of the variance in shoulder disability category membership.

\section{Genotype/allele frequency distributions between shoulder pain/disability categories}

For both shoulder pain and shoulder disability, no significant differences in the genotype/allele frequency distributions were noted between the no - low and moderate-high categories for all SNPs: KDR (VEGF-R2) (rs2305948 C $>\mathrm{T}$; rs7667298 $\mathrm{C}>\mathrm{T}$ ), NOS3 (rs1549758 C>T), MMP2 (rs708269 A>T), THBS2 (rs9766678 $\mathrm{A}>\mathrm{G}$ ) and TIMP3 (rs5754312 $\mathrm{T}>\mathrm{A}$; rs715572 G>A) (Tables 6 and 7). The genotype distributions for the no-low category for both shoulder pain and shoulder disability were in HWE for all SNPs $(P>0.05)$ (Tables 6 and 7). The genotype distributions for the moderate-high category for both shoulder pain and shoulder disability were also in HWE for all SNPs $(P>0.05)$, although the $P$-values for rs 7667298 and rs9766678 were $<0.10$. (Tables 6 and 7 ).

\section{KDR and TIMP3 inferred haplotype frequency distributions between shoulder pain/disability categories}

There were no significant differences in the frequency distribution of the inferred $K D R$ haplotypes between the no-low and moderate-high shoulder pain categories $(P>0.05)$ (Table 8). However, the frequencies of the inferred $K D R$ haplotypes differed significantly between the no - low and moderate-high shoulder disability categories $(P=0.024)$ (Table 9). In particular, the $K D R$
"TT" inferred haplotype was significantly overrepresented in the no - low shoulder disability category relative to the moderate - high disability category $(P=0.014,11.4 \%$ vs $0.0 \%$ ) (Table 9 and Figure 1 ).

There were no significant differences in the frequency distribution of the inferred TIMP 3 haplotypes between the no-low and moderate-high shoulder pain categories $(P>0.05)$ (Table 8). Similarly, there were no significant differences in the frequency distribution of the inferred TIMP3 haplotypes between the no-low and moderatehigh shoulder disability categories $(P>0.05)$ (Table 9).

\section{Bivariate regression analysis for inferred KDR haplotypes to predict shoulder disability including participants' age}

After adjusting for age, only a trend $(P=0.052)$ was observed in the distribution of inferred $K D R$ haplotypes between shoulder disability categories (Table 10). In the regression analysis for inferred $K D R$ haplotypes, each dose of the "TT" haplotype increased the odds of being in the no-low shoulder disability category by $100 \%$ (OR: $0.00, P=0.014$ ) (Table 10$)$.

\section{Discussion}

Our study suggests an association between functional polymorphisms within $K D R$ and shoulder disability following breast cancer treatment among mixed ancestry individuals. Although the independent $K D R$ SNPs were not significantly associated with shoulder disability, inferred haplotypes have implicated a genomic interval within $K D R$ to be associated with shoulder disability. ${ }^{57}$ Such an effect is especially important considering that both SNPs are functional ${ }^{58,59}$ and one of the SNPs has previously been implicated in other forms of connective tissue pathology susceptibility. ${ }^{18}$ To the best of our 
Table 6 Genotype and minor allele frequency distributions, and $P$-values for Hardy-Weinberg (HWE) exact test of the KDR rs7667298 C>T, KDR rs2305948 C>T, MMP2 rs708269 A>T, NOS3 rsl549758 C>T, THBS2 rs9766678 A>G, TIMP3 rs7I5572 G>A, and TIMP3 rs57543I2 T>A polymorphisms in mixed ancestry participants with no-low pain and moderate-high pain in the shoulder following breast cancer treatment

\begin{tabular}{|c|c|c|c|c|}
\hline & & $\begin{array}{l}\text { No-low pain } \\
(n=169)\end{array}$ & $\begin{array}{l}\text { Moderate-high pain } \\
(n=5 I)\end{array}$ & $P$-value \\
\hline \multirow{6}{*}{$\begin{array}{l}\text { KDR } \\
\text { rs7667298 }\end{array}$} & & & & \\
\hline & $\mathrm{C} / \mathrm{C}$ & $26.0(44)$ & $4 I .2(2 I)$ & \\
\hline & $\mathrm{C} / \mathrm{T}$ & $50.3(85)$ & $35.3(18)$ & 0.090 \\
\hline & $\mathrm{T} / \mathrm{T}$ & $23.7(40)$ & $23.5(12)$ & \\
\hline & C Allele & 5I.I (I73) & $58.8(60)$ & 0.213 \\
\hline & HWE & 1.000 & 0.080 & \\
\hline \multirow[t]{5}{*}{ rs2305948 } & $\mathrm{C} / \mathrm{C}$ & 78.1 (I32) & $80.4(4 I)$ & \\
\hline & $\mathrm{C} / \mathrm{T}$ & $21.3(36)$ & $19.6(10)$ & 0.882 \\
\hline & $\mathrm{T} / \mathrm{T}$ & $0.6(I)$ & $0(0)$ & \\
\hline & T Allele & I I.2 (38) & $9.8(10)$ & 0.856 \\
\hline & HWE & 0.698 & 1.000 & \\
\hline \multicolumn{5}{|l|}{ MMP2 } \\
\hline \multirow[t]{5}{*}{ rs708269 } & $\mathrm{A} / \mathrm{A}$ & $51.5(87)$ & $49.0(25)$ & \\
\hline & $\mathrm{A} / \mathrm{T}$ & $4 I .4(70)$ & $4 I .2(2 I)$ & 0.820 \\
\hline & $\mathrm{T} / \mathrm{T}$ & $7.1(12)$ & $9.8(5)$ & \\
\hline & T Allele & $27.8(94)$ & $30.4(31)$ & 0.618 \\
\hline & HWE & 0.848 & 1.000 & \\
\hline \multicolumn{5}{|l|}{ NOS3 } \\
\hline \multirow[t]{5}{*}{ rs I549758 } & $\mathrm{C} / \mathrm{C}$ & $72.2(122)$ & 64.7 (33) & \\
\hline & $\mathrm{C} / \mathrm{T}$ & $26.0(44)$ & $31.4(16)$ & 0.493 \\
\hline & $\mathrm{T} / \mathrm{T}$ & I.8 (3) & $3.9(2)$ & \\
\hline & T Allele & $24.3(82)$ & $19.6(20)$ & 0.280 \\
\hline & HWE & 1.000 & 1.000 & \\
\hline \multicolumn{5}{|l|}{ THBS2 } \\
\hline \multirow[t]{5}{*}{ rs9766678 } & $\mathrm{A} / \mathrm{A}$ & $44.4(75)$ & 45.1 (23) & \\
\hline & $A / G$ & 46.7 (79) & 37.3 (19) & 0.192 \\
\hline & $\mathrm{G} / \mathrm{G}$ & $8.9(15)$ & I7.6 (9) & \\
\hline & G Allele & $32.2(109)$ & 36.3 (37) & 0.473 \\
\hline & HWE & 0.481 & 0.222 & \\
\hline \multicolumn{5}{|l|}{ TIMP3 } \\
\hline \multirow[t]{5}{*}{ rs7I5572 } & $\mathrm{G} / \mathrm{G}$ & $69.2(117)$ & $68.6(35)$ & \\
\hline & $A / G$ & 27.8 (47) & $27.5(14)$ & 0.945 \\
\hline & $\mathrm{A} / \mathrm{A}$ & $3.0(5)$ & $3.9(2)$ & \\
\hline & A Allele & $16.9(57)$ & $17.6(18)$ & 0.881 \\
\hline & HWE & 1.000 & 0.637 & \\
\hline \multirow[t]{5}{*}{ rs5754312 } & $\mathrm{T} / \mathrm{T}$ & $30.2(5 I)$ & 33.3 (I7) & \\
\hline & $\mathrm{A} / \mathrm{T}$ & $53.3(90)$ & $49.0(25)$ & 0.866 \\
\hline & $\mathrm{A} / \mathrm{A}$ & $16.6(28)$ & $17.6(9)$ & \\
\hline & A Allele & $43.2(146)$ & $42.2(43)$ & 0.909 \\
\hline & HWE & 0.347 & 1.000 & \\
\hline
\end{tabular}

Notes: Genotype and allele frequencies are expressed as a percentage with the number of participants $(n)$ in parentheses. $P$-values for the exact test of Hardy-Weinberg equilibrium for each of the categories are included in the table. $P$-values in bold typeset indicate significance $(P<0.05)$.

Abbreviation: HWE, Hardy-Weinberg equilibrium. 
Table 7 Genotype and minor allele frequency distributions, and $P$-values for Hardy-Weinberg (HWE) exact test of the KDR rs7667298 C>T, KDR rs2305948 C>T, MMP2 rs708269 A>T, NOS3 rsI549758 C>T, THBS2 rs9766678 A>G, TIMP3 rs7I5572 G>A, and TIMP3 rs57543 12 T>A polymorphisms in mixed ancestry participants with no-low disability and moderate-high disability in the shoulder following breast cancer treatment

\begin{tabular}{|c|c|c|c|c|}
\hline & & No-low disability $(n=\mid 83)$ & $\begin{array}{l}\text { Moderate-high disability } \\
(n=37)\end{array}$ & $P$-value \\
\hline \multicolumn{5}{|l|}{ KDR } \\
\hline \multirow[t]{5}{*}{ rs7667298 } & $\mathrm{C} / \mathrm{C}$ & $26.8(49)$ & $43.2(16)$ & \\
\hline & $\mathrm{C} / \mathrm{T}$ & $49.2(90)$ & $35.1(13)$ & 0.134 \\
\hline & $\mathrm{T} / \mathrm{T}$ & $24.0(44)$ & $21.6(8)$ & \\
\hline & C Allele & $51.4(188)$ & $60.8(45)$ & 0.160 \\
\hline & HWE & 0.882 & 0.163 & \\
\hline \multirow[t]{5}{*}{ rs2305948 } & $\mathrm{C} / \mathrm{C}$ & $76.5(140)$ & $89.2(33)$ & \\
\hline & $\mathrm{C} / \mathrm{T}$ & $23.0(42)$ & $10.8(4)$ & 0.269 \\
\hline & $\mathrm{T} / \mathrm{T}$ & $0.5(I)$ & $0.0(0)$ & \\
\hline & T Allele & $12.0(44)$ & $5.4(4)$ & 0.105 \\
\hline & HWE & 0.479 & 1.000 & \\
\hline \multicolumn{5}{|l|}{ MMP2 } \\
\hline \multirow[t]{5}{*}{ rs708269 } & $\mathrm{A} / \mathrm{A}$ & $51.9(95)$ & $45.9(17)$ & \\
\hline & $\mathrm{A} / \mathrm{T}$ & $40.4(74)$ & $45.9(17)$ & 0.799 \\
\hline & $\mathrm{T} / \mathrm{T}$ & $7.7(14)$ & $8.1(3)$ & \\
\hline & T Allele & $27.9(102)$ & $31.1(23)$ & 0.574 \\
\hline & HWE & 1.000 & 1.000 & \\
\hline \multicolumn{5}{|l|}{ NOS3 } \\
\hline \multirow[t]{5}{*}{ rsI549758 } & $\mathrm{C} / \mathrm{C}$ & $71.0(130)$ & $67.6(25)$ & \\
\hline & $\mathrm{C} / \mathrm{T}$ & $27.3(50)$ & $27.0(10)$ & 0.459 \\
\hline & $\mathrm{T} / \mathrm{T}$ & $1.6(3)$ & $5.4(2)$ & \\
\hline & T Allele & $15.3(56)$ & $18.9(14)$ & 0.485 \\
\hline & HWE & 0.774 & 0.584 & \\
\hline \multicolumn{5}{|l|}{ THBS2 } \\
\hline \multirow[t]{5}{*}{ rs9766678 } & $\mathrm{A} / \mathrm{A}$ & $43.2(79)$ & $51.4(19)$ & \\
\hline & $A / G$ & 47.5 (87) & 29.7 (II) & 0.077 \\
\hline & $\mathrm{G} / \mathrm{G}$ & $9.3(17)$ & I8.9 (7) & \\
\hline & G Allele & $33.1(121)$ & $33.8(25)$ & 0.893 \\
\hline & HWE & 0.403 & 0.061 & \\
\hline \multicolumn{5}{|l|}{ TIMP3 } \\
\hline \multirow[t]{5}{*}{ rs7।5572 } & $\mathrm{G} / \mathrm{G}$ & $68.9(126)$ & $70.3(26)$ & \\
\hline & $A / G$ & $28.4(52)$ & $24.3(9)$ & 0.671 \\
\hline & $\mathrm{A} / \mathrm{A}$ & $2.7(5)$ & $5.4(2)$ & \\
\hline & A Allele & 16.9 & $17.6(13)$ & 0.867 \\
\hline & HWE & 1.000 & 0.286 & \\
\hline \multirow[t]{5}{*}{ rs57543I2 } & $T / T$ & $30.6(56)$ & $32.4(12)$ & \\
\hline & $\mathrm{A} / \mathrm{T}$ & $51.9(95)$ & $54.1(20)$ & 0.833 \\
\hline & $\mathrm{A} / \mathrm{A}$ & I7.5 (32) & I3.5 (5) & \\
\hline & A Allele & 43.4 (159) & $40.5(30)$ & 0.700 \\
\hline & HWE & 0.547 & 0.732 & \\
\hline
\end{tabular}

Notes: Genotype and allele frequencies are expressed as a percentage with the number of participants $(n)$ in parentheses. $P$-values for the exact test of Hardy-Weinberg equilibrium for each of the categories are included in the table. $P$-values in bold typeset indicate statistical significance $(P<0.05)$.

Abbreviation: HWE, Hardy-Weinberg equilibrium. 
Table 8 Inferred KDR haplotype frequency distribution for shoulder pain categories

\begin{tabular}{|c|c|c|c|c|c|c|c|}
\hline \multirow[t]{2}{*}{ Gene } & \multicolumn{2}{|c|}{ Haplotype } & \multicolumn{2}{|c|}{ Frequency (\%) } & \multirow[t]{2}{*}{ HS } & \multicolumn{2}{|l|}{$P$-value } \\
\hline & & & $\begin{array}{l}\text { No-low pain } \\
(n=169)\end{array}$ & $\begin{array}{l}\text { Moderate-high pain } \\
(n=5 I)\end{array}$ & & Global & Specific \\
\hline \multirow{5}{*}{$K D R$} & rs2305948 & rs7667298 & & & & 0.206 & \\
\hline & $\mathrm{T}$ & $\mathrm{T}$ & 10.6 & 6.3 & -0.96 & & 0.337 \\
\hline & C & $\mathrm{T}$ & 38.2 & 34.8 & -0.80 & & 0.423 \\
\hline & C & $C$ & 50.5 & 55.4 & 1.06 & & 0.288 \\
\hline & rs715572 & rs57543I2 & & & & 0.507 & \\
\hline \multirow[t]{3}{*}{ TIMP3 } & G & A & 30.5 & 25.8 & -0.67 & & 0.500 \\
\hline & G & $\mathrm{T}$ & 56.6 & 56.5 & 0.50 & & 0.619 \\
\hline & $A$ & $A$ & 12.7 & 16.3 & 0.66 & & 0.512 \\
\hline
\end{tabular}

Notes: Haplotype frequencies are expressed as percentages. $P$-values in bold typeset indicate statistical significance $(P<0.05)$.

Abbreviation: HS, Haplotype score.

Table 9 Inferred KDR haplotype frequency distribution for shoulder disability categories

\begin{tabular}{|c|c|c|c|c|c|c|c|}
\hline \multirow[t]{2}{*}{ Gene } & \multicolumn{2}{|c|}{ Haplotype } & \multicolumn{2}{|l|}{ Frequency (\%) } & \multirow[t]{2}{*}{ HS } & \multicolumn{2}{|l|}{$P$-value } \\
\hline & & & $\begin{array}{l}\text { No-low disability } \\
(n=183)\end{array}$ & $\begin{array}{l}\text { Moderate-high disability } \\
(n=37)\end{array}$ & & Global & Specific \\
\hline \multirow{5}{*}{$K D R$} & rs2305948 & rs7667298 & & & & 0.024 & \\
\hline & $\mathrm{T}$ & $\mathrm{T}$ & 11.4 & 0.00 & -2.45 & & 0.014 \\
\hline & $\mathrm{C}$ & $\mathrm{T}$ & 37.2 & 39.2 & -0.14 & & 0.885 \\
\hline & $C$ & C & 50.8 & 55.4 & 1.15 & & 0.250 \\
\hline & rs7I5572 & rs57543I2 & & & & 0.740 & \\
\hline \multirow[t]{3}{*}{ TIMP3 } & G & A & 30.3 & 24.9 & -0.77 & & $0.44 I$ \\
\hline & A & A & 13.2 & 15.7 & 0.37 & & 0.709 \\
\hline & G & T & 52.8 & 57.6 & 0.63 & & 0.529 \\
\hline
\end{tabular}

Notes: Haplotype frequencies are expressed as percentages. $P$-values in bold typeset indicate statistical significance $(P<0.05)$.

Abbreviation: HS, Haplotype score.

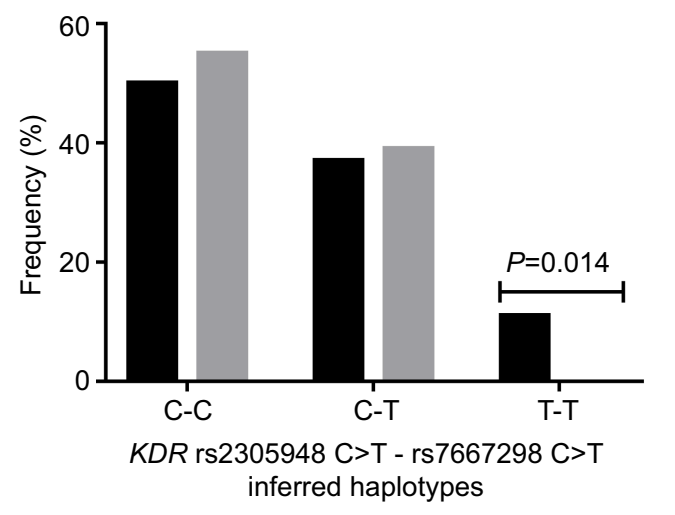

No - low disability $(\mathrm{n}=183)$

Moderate - high disability

$(n=37)$

Global $P=0.024$

Figure I The frequency distribution of the KDR ( $r 2305948$ C>T-rs7667298 C>T) inferred haplotype between no-low and moderate-high disability participants. Frequency distribution of inferred haplotypes constructed from the rs2305948 (C>T) and rs7667298 (C>T) variants in the no - low and moderate - high disability groups. Significant differences in haplotype frequencies between groups are depicted on the graph, with non-adjusted $P$-values. The number of participants ( $n$ ) in each group is in parentheses. 
Table 10 Bivariate logistic regression analysis for inferred KDR haplotypes to predict shoulder disability category membership, including participants' age at consent

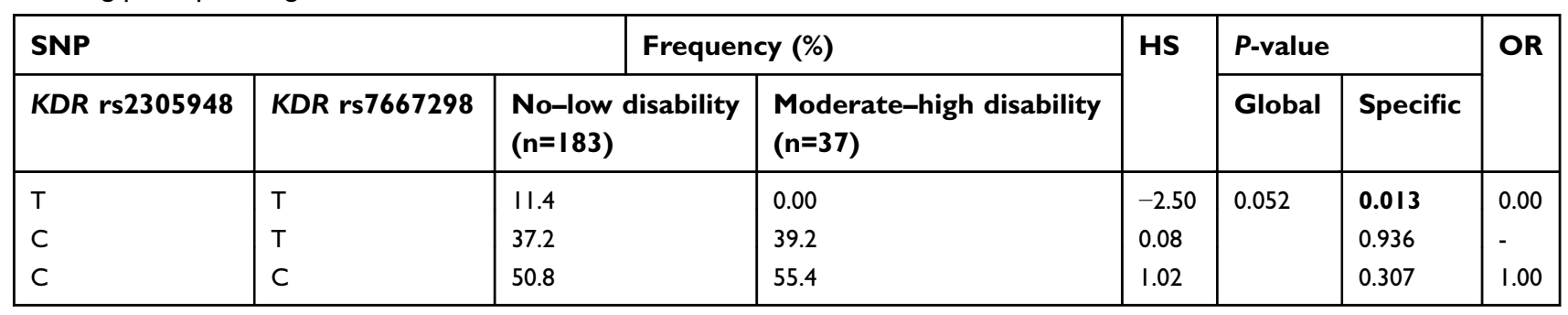

Notes: Haplotype frequencies are expressed as percentages. $P$-values in bold typeset indicate statistical significance $(P<0.05)$.

Abbreviations: HS, Haplotype score; OR, Odds ratio.

knowledge, this study is the first to evaluate associations between polymorphisms in genes involved in angiogenesis and shoulder pain/disability in breast cancer survivors.

In the bivariate analyses of clinical and demographic data, only participants' age at consent was significantly associated with both shoulder pain and shoulder disability following breast cancer treatment. This association is consistent with previous reports on age and persistent pain following breast cancer treatment $^{12,60,61}$. The bivariate regression models for shoulder pain or disability explained only $5.2 \%$ and $2.5 \%$ of the variance in pain or disability category membership, respectively (Tables 3 and 4). Contrary to previous reports, ${ }^{12,62}$ adjuvant radiotherapy was not significantly associated with shoulder pain or shoulder disability in our study. This may reflect changes in the etiology of shoulder pain and disability with long follow-up periods, which in our cohort was $>3$ years on average (Tables 1 and 2). Furthermore, a trend contrary to previous reports, ${ }^{2,5,10,46}$ of higher frequency of the more aggressive mastectomy compared to the conservative wide local excision (WLE) among shoulder pain controls was noted in our study. This finding may perhaps be specific to our cohort or primary outcomes: shoulder pain and shoulder disability. As with other studies, ${ }^{12,14}$ however, our demographic and clinical data suggest that variability in the occurrence of shoulder pain or shoulder disability is not largely explained by factors related to surgical management or adjuvant treatment.

Angiogenesis signaling has links to molecular signaling pathways that are important in shoulder complex pathology such as the inflammatory pathway, fibrogenesis and ECM remodeling. ${ }^{27,28}$ The inflammatory pathway has potent nociceptive effects which may contribute to shoulder pain. ${ }^{27,63,64}$ In addition, aberrant
ECM production or fibrosis can potentially contribute to stiffness in the shoulder joint capsule which can lead to reductions in range of motion. ${ }^{65}$ Our findings support the body of evidence implicating the angiogenesis pathway in non-cancer musculoskeletal conditions such as tendon injuries or tendinopathy ${ }^{17,18}$ and rotator cuff disease (RCD). ${ }^{19,20}$

Our findings suggest that the "TT" haplotype for $K D R \quad$ rs2305948 $\mathrm{C}>\mathrm{T}-\mathrm{rs} 7667298 \quad \mathrm{C}>\mathrm{T}$ may have a protective effect on the occurrence of shoulder disability following breast cancer treatment. This haplotype was completely absent among moderate-high shoulder disability participants (Table 10 and Figure 1). KDR encodes VEGF-R2, the main angiogenesis signaling receptor that mediates endothelial cell survival, activation, proliferation and migration. ${ }^{27,28}$ Both SNPs for the KDR "TT" haplotype have been associated with coronary heart $\operatorname{disease}^{66}$ and notably, rs2305948 "T" allele has been associated with reduced tendinopathy risk. ${ }^{18} K D R$ rs2305948 is a missense variant ( $\Delta$ amino acid - valine/isoleucine) which has been proposed to be functional. ${ }^{58}$ Although both amino acids are non-polar, the Isoleucine variant (" $T$ " allele for rs2305948) has been reported to reduce VEGF-A binding efficiency. ${ }^{58}$ Interestingly, the "TT" genotype of rs7667298 has been shown to increase $K D R$ expression. ${ }^{59}$ However, the biological functional significance of this haplotype on the angiogenesis pathway remains unclear. Based on the previous functional evidence, ${ }^{58,59}$ we suggest that this "TT" haplotype may be indicating a pro-angiogenic profile. It can also be argued that the SNPs implicated in this haplotype could be in LD to other SNPs that may underlie the occurrence of shoulder disability. The frequency of the "T" allele for both KDR SNPs was lower for the moderate-high shoulder disability category compared 
to the no-low category although this difference did not approach statistical significance (Table 7). The pathophysiology that underlies shoulder disability after breast cancer treatment may be different from that which characterizes non-cancer shoulder conditions. Unlike rotator cuff disease and rotator cuff tendinopathy which are characterized by foreshortening of the pectoral girdle muscles and soft tissues, and weakening or degeneration of tendon structure, respectively, shoulder disability in our patient group could be a result of soft tissue fibrosis. ${ }^{34,67}$ KDR signaling through VEGF-A up-regulates MMPs which in turn may alter, and perhaps weaken, tendon structure leading to movement dysfunction.

Our study was not without limitations. Firstly, the sample size is small and underpowered (power $<80 \%$ ) for small effect sizes $(\mathrm{OR}=1.5)$ except for allele frequencies $\geq 0.40$ (Table S3 and S4). Larger sample sizes may detect significant differences in other clinical and genotypic characteristics included in this study. Secondly, no direct measurements of protein or DNA expression were performed to provide additional data on the mechanisms that underlie the development of shoulder pain/disability. Thirdly, there was no wide score gap separating the two shoulder pain/disability categories. Therefore, close to the boundary score of 30 , some individuals with similar shoulder pain/disability characteristics may be in different pain/disability categories. Future studies focusing on extreme phenotypes may increase effect sizes of these associations. Finally, ethnicity was determined by self-report which is less reliable than genomic estimates and therefore, there is a possibility of undetermined population stratification in our sample.

In conclusion, our findings provide preliminary evidence of an association between polymorphisms in genes involved in angiogenesis and the occurrence of shoulder disability in women following breast cancer treatment. Future studies in independent populations with larger sample sizes are warranted to further characterize the observations and explore the potential biological mechanisms.

\section{Ethics}

This study received ethical approval from the Human Research Ethics Committee at the University of Cape Town (HREC REF: 650/2016) and was performed in accordance with the principles of the Declaration of Helsinki, the South African Good Clinical Practice (GCP) guidelines and the laws of South Africa.

\section{Acknowledgments}

This study was funded in part by the University of Cape Town Research Council, the Medical Research Council and the National Research Foundation (NRF). TSM was funded by the University of Cape Town and the National Research Foundation.

\section{Disclosure}

Opinions expressed and conclusions arrived at, are those of the author and are not necessarily to be attributed to the funders. The authors declare no conflicts of interest with respect to the research, authorship, and/or publication of this article.

\section{References}

1. Hayes SC, Johansson K, Stout NL, et al. Upper-body morbidity after breast cancer: incidence and evidence for evaluation, prevention, and management within a prospective surveillance model of care. Cancer. 2012;118(8 Suppl):2237-2249. doi:10.1002/cncr.26523

2. Shamley D, Lascurain-Aguirrebena I, Oskrochi R, Srinaganathan R. Shoulder morbidity after treatment for breast cancer is bilateral and greater after mastectomy. Acta Oncol. 2012;51(8):1045-1053. doi:10.3109/0284186X.2012.695087

3. Schmitz KH, Speck RM, Rye SA, DiSipio T, Hayes SC. Prevalence of breast cancer treatment sequelae over 6 years of follow-up: the pulling through study. Cancer. 2012;118(8 Suppl):2217-2225. doi:10.1002/cncr.26523

4. Peuckmann V, Ekholm O, Rasmussen NK, et al. Chronic pain and other sequelae in long-term breast cancer survivors: nationwide survey in Denmark. Eur J Pain. 2009;13(5):478-485. doi:10.1016/j. ejpain.2008.05.015

5. Hidding JT, Beurskens CHG, van der Wees PJ, van Laarhoven HWM. Nijhuis-van der Sanden MWG. Treatment related impairments in arm and shoulder in patients with breast cancer: a systematic review. PLoS One. 2014;9(5):1-17. doi:10.1371/journal.pone. 0096748

6. Gartner R, Jensen MB, Nielsen J, Ewertz M, Kroman N, Kehlet H. Prevalence of and factors associated with persistent pain following breast cancer surgery. Jama. 2009;302(18):1985-1992.

7. Shamley D, Srinaganathan R, Oskrochi R, Lascurain-Aguirrebena I, Sugden E. Three-dimensional scapulothoracic motion following treatment for breast cancer. Breast Cancer Res Treat. 2009;118 (2):315-322. doi:10.1007/s10549-008-0240-x

8. Nesvold IL, Fossa SD, Holm I, Naume B, Dahl AA. Arm/shoulder problems in breast cancer survivors are associated with reduced health and poorer physical quality of life. Acta Oncol. 2010;49 (3):347-353. doi:10.3109/02841860903287213

9. Nesvold IL, Reinertsen KV, Fossa SD, Dahl AA. The relation between arm/shoulder problems and quality of life in breast cancer survivors: a cross-sectional and longitudinal study. J Cancer Surviv. 2011;5(1):62-72. doi:10.1007/s11764-010-0156-4

10. Sagen A, Kaaresen R, Sandvik L, Thune I, Risberg MA. Upper limb physical function and adverse effects after breast cancer surgery: a prospective 2.5-year follow-up study and preoperative measures. Arch Phys Med Rehabil. 2014;95(5):875-881 877.

11. Lee TS, Kilbreath SL, Refshauge KM, Herbert RD, Beith JM. Prognosis of the upper limb following surgery and radiation for breast cancer. Breast Cancer Res Treat. 2008;110(1):19-37. doi:10.1007/s10549-007-9710-9 
12. Wang L, Guyatt GH, Kennedy SA, et al. Predictors of persistent pain after breast cancer surgery: a systematic review and meta-analysis of observational studies. Cmaj. 2016;188(14):E352-e361.

13. Smoot B, Paul SM, Aouizerat BE, et al. Predictors of altered upper extremity function during the first year after breast cancer treatment. Am J Phys Med Rehabil. 2016. doi:10.1097/PHM.000000000 0000455

14. Bell RJ, Robinson PJ, Nazeem F, et al. Persistent breast pain 5 years after treatment of invasive breast cancer is largely unexplained by factors associated with treatment. J Cancer Surviv. 2014;8(1):1-8. doi:10.1007/s11764-013-0306-6

15. Adriaenssens N, Vinh-Hung V, Miedema G, et al. Early contralateral shoulder-arm morbidity in breast cancer patients enrolled in a randomized trial of post-surgery radiation therapy. Breast Cancer. 2012;6:79-93.

16. Shamley DR, Srinanaganathan R, Weatherall R, et al. Changes in shoulder muscle size and activity following treatment for breast cancer. Breast Cancer Res Treat. 2007;106(1):19-27.

17. Oliva F, Via AG, Maffulli N. Role of growth factors in rotator cuff healing. Sports Med Arthrosc. 2011;19(3):218-226.

18. Salles JI, Duarte MEL, Guimarães JM, et al. Vascular endothelial growth factor receptor-2 polymorphisms have protective effect agains the development of tendinopathy in volleyball athletes. PLoS One. 2016;11(12):e0167717. doi:10.1371/journal.pone.0167717

19. Savitskaya YA, Izaguirre A, Sierra L, et al. Effect of angiogenesis-related cytokines on rotator cuff disease: the search for sensitive biomarkers of early tendon degeneration. Clin Med Insights Arthritis Musculoskelet Disord. 2011;4:43-53. doi:10.4137/ CMAMD.S7071

20. Hegedus EJ, Cook C, Brennan M, Wyland D, Garrison JC, Driesner D. Vascularity and tendon pathology in the rotator cuff: a review of literature and implications for rehabilitation and surgery. $\mathrm{Br} J$ Sports Med. 2010;44(12):838-847. doi:10.1136/bjsm.2008.049783

21. Lundgreen K, Ø L, Scott A, Engebretsen L. Increased levels of apoptosis and p53 in partial-thickness supraspinatus tendon tears. Knee Surg Sports Traumatol Arthrosc. 2013;21(7):1636-1641.

22. Yuan J, Murrell GAC, Wei AQ, Wang MX. Apoptosis in rotator cuff tendonopathy. J Orthop Res. 2002;20(6):1372-1379. doi:10.1016/ S0736-0266(02)00071-2

23. Del Buono A, Oliva F, Osti L, Maffulli N. Metalloproteases and tendinopathy. Muscles Ligaments Tendons J. 2013;3(1):51-57.

24. Riley GP, Curry V, DeGroot J, et al. Matrix metalloproteinase activities and their relationship with collagen remodelling in tendon pathology. Matrix Biol. 2002;21(2):185-195. doi:10.1016/S0945053X(01)00196-2

25. Benson RT, McDonnell SM, Knowles HJ, Rees JL, Carr AJ, Hulley PA. Tendinopathy and tears of the rotator cuff are associated with hypoxia and apoptosis. J Bone Joint Surg Br. 2010;92 (3):448-453. doi:10.1302/0301-620X.92B3.23074

26. Mafu TS, September AV, Shamley D. The potential role of angiogenesis in the development of shoulder pain, shoulder dysfunction, and lymphedema after breast cancer treatment. Cancer Manag Res. 2018;10:81-90. doi:10.2147/CMAR.S151714

27. Szade A, Grochot-Przeczek A, Florczyk U, Jozkowicz A, Dulak J. Cellular and molecular mechanisms of inflammation-induced angiogenesis. IUBMB Life. 2015;67(3):145-159. doi:10.1002/ iub. 1375

28. Carmeliet P, Jain RK. Molecular mechanisms and clinical applications of angiogenesis. Nature. 2011;473(7347):298-307. doi:10.1038/ nature 10079

29. Bokhari AR, Murrell GAC. The role of nitric oxide in tendon healing. J Shoulder Elbow Surg. 2012;21(2):238-244.

30. Szomor Z, Wang M, Kruller A, et al. Differential expression of cytokines and nitric oxide synthase isoforms in human rotator cuff bursae. Ann Rheum Dis. 2001;60(4):431-432.
31. Szomor ZL, Appleyard RC, Murrell GAC. Overexpression of nitric oxide synthases in tendon overuse. J Orthop Res. 2006;24(1):80-86. doi:10.1002/jor.20080

32. Ebaugh D, Spinelli B, Schmitz KH. Shoulder impairments and their association with symptomatic rotator cuff disease in breast cancer survivors. Med Hypotheses. 2011;77(4):481-487. doi:10.1016/j. mehy.2011.09.023

33. Stubblefield MD, Custodio CM. Upper-extremity pain disorders in breast cancer. Arch Phys Med Rehabil. 2006;87(3, Supplement):96-99.

34. Stubblefield MD, Keole N. Upper body pain and functional disorders in patients with breast cancer. Pm R. 2014;6(2):170-183. doi:10.1016/j.pmrj.2013.08.605

35. Rundhaug JE. Matrix metalloproteinases, angiogenesis, and cancer. Commentary re: A C Lockhart et al, reduction of wound angiogenesis in patients treated with BMS-275291, a broad spectrum matrix metalloproteinase inhibitor. Clin Cancer Res. 2003;9(2):551-554. 9: 00-00, 2003.

36. Kroll J, Waltenberger J. VEGF-A induces expression of eNOS and iNOS in endothelial cells via VEGF receptor-2 (KDR). Biochem Biophys Res Commun. 1998;252(3):743-746.

37. Lawler PR, Lawler J. Molecular basis for the regulation of angiogenesis by thrombospondin-1 and -2. Cold Spring Harb Perspect Med. 2012;2(5):a006627. doi:10.1101/cshperspect.a006627

38. Arpino V, Brock M, Gill SE. The role of TIMPs in regulation of extracellular matrix proteolysis. Matrix Biol. 2015;44-46:247-254.

39. Lahiri DK, Nurnberger JI. A rapid non-enzymatic method for the preparation of HMW DNA from blood for RFLP studies. Nucleic Acids Res. 1991;19(19):5444. doi:10.1093/nar/19.19.5444

40. MacDermid JC, Solomon P, Prkachin K. The shoulder pain and disability index demonstrates factor, construct and longitudinal validity. $B M C$ Musculoskelet Disord. 2006;7:12. doi:10.1186/1471-2474-7-12

41. Roach KE, Budiman-Mak E, Songsiridej N, Lertratanakul Y. Development of a shoulder pain and disability index. Arthritis Care Res. 1991;4(4):143-149.

42. Tengrup I, Tennvall-Nittby L, Christiansson I, Laurin M. Arm morbidity after breast-conserving therapy for breast cancer. Acta Oncol. 2000;39(3):393-397. doi:10.1080/028418600750013177

43. Johansen S, Foss K, Nesvold IL, Malinen E, Foss SD. Arm and shoulder morbidity following surgery and radiotherapy for breast cancer. Acta Oncol (Madr). 2014;53(4):521-529.

44. Arndt V, Stegmaier C, Ziegler H, Brenner H. A population-based study of the impact of specific symptoms on quality of life in women with breast cancer 1 year after diagnosis. Cancer. 2006;107 (10):2496-2503. doi:10.1002/(ISSN)1097-0142

45. Engel J, Kerr J, Schlesinger-Raab A, Sauer H, Holzel D. Axilla surgery severely affects quality of life: results of a 5-year prospective study in breast cancer patients. Breast Cancer Res Treat. 2003;79(1):47-57. doi:10.1023/A:1023330206021

46. Nesvold IL, Dahl AA, Lokkevik E, Marit Mengshoel A, Fossa SD. Arm and shoulder morbidity in breast cancer patients after breast-conserving therapy versus mastectomy. Acta Oncol. 2008;47 (5):835-842. doi:10.1080/02841860801961257

47. Hayes SC, Rye S, Battistutta D, DiSipio T, Newman B. Upper-body morbidity following breast cancer treatment is common, may persist longer-term and adversely influences quality of life. Health Qual Life Outcomes. 2010;8:92. doi:10.1186/1477-7525-8-92

48. Dahl AA, Nesvold IL, Reinertsen KV, Fossa SD. Arm/shoulder problems and insomnia symptoms in breast cancer survivors: cross-sectional, controlled and longitudinal observations. Sleep Med. 2011;12(6):584-590. doi:10.1016/j.sleep.2011.01.011

49. Quanto [Computer Program]. Version 1.2.4.. Los Angeles: University of Southern California; 2009.

50. Dell, Inc. Dell Statistica (Data Analysis Software System) [Computer Program]. Version Version 13. Tulsa, OK 74104, USA: Dell Inc.; 2016. 
51. R Core Team. R: A Language and Environment for Statistical Computing [Computer Program]. Vienna: R Foundation for Statistical Computing; 2017. Available from: www.R-project.org/

52. Warnes G, Gorjanc G, Leisch F, Man M.Package 'Genetics': Population Genetics [Computer Program]. Version 1.3.8.1. 2013. Available from: https://CRAN.R-project.org/package=genetics

53. Schaid DJ, Rowland CM, Tines DE, Jacobson RM, Poland GA. Score tests for association between traits and haplotypes when linkage phase is ambiguous. Am J Hum Genet. 2002;70(2):425-434. doi:10.1086/340449

54. Sinnwell JP, Schaid DJ. Haplo Stats (Version 1.5.0): Statistical Methods for Haplotypes When Linkage Phase Is Ambiguous. Mayo Clinic Division of Health Sciences Research: Rochester, MN, USA; 2011. Available from: https://CRAN.R-project.org/package=haplo.stats

55. González J R, Armengol L, Guinó E, Solé X, Moreno V.Package 'Snpassoc': SNPs-based Whole Genome Association Studies [Computer Program]. Version 1.9-2. 2014. Available from: https:// CRAN.R-project.org/package $=\mathrm{SNPassoc}$

56. Barbosa A.M., Brown J.A., Jimenez-Valverde A., Real R.Package 'Modeva': Model Evaluation and Analysis [Computer Program]. Version 1.3.2. 2016. Available from: https://CRAN.R-project.org/ package $=$ modEvA

57. Zaykin DV, Westfall PH, Young SS, Karnoub MA, Wagner MJ, Ehm MG. Testing association of statistically inferred haplotypes with discrete and continuous traits in samples of unrelated individuals. Hum Hered. 2002;53(2):79-91.

58. Wang Y, Zheng Y, Zhang W, et al. Polymorphisms of KDRGene are associated with coronary heart disease. J Am Coll Cardiol. 2007;50 (8):760-767. doi:10.1016/j.jacc.2007.04.074

59. An S-J, Chen Z-H, Lin Q-X, et al. The $-271 \mathrm{G}>\mathrm{A}$ polymorphism of kinase insert domain-containing receptor gene regulates its transcription level in patients with non-small cell lung cancer. BMC Cancer. 2009;9:144. doi:10.1186/1471-2407-9-144
60. Stephens K, Cooper BA, West C, et al. Associations between cytokine gene variations and severe persistent breast pain in women following breast cancer surgery. J Pain. 2014;15(2):169-180. doi:10.1016/j.jpain.2013.09.015

61. Doong SH, Dhruva A, Dunn LB, et al. Associations between cytokine genes and a symptom cluster of pain, fatigue, sleep disturbance, and depression in patients prior to breast cancer surgery. Biol Res Nurs. 2015;17(3):237-247. doi:10.1177/ 1099800414539385

62. Langford DJ, Paul SM, West C, et al. Persistent breast pain following breast cancer surgery is associated with persistent sensory changes, pain interference, and functional impairments. J Pain. 2014;15 (12):1227-1237. doi:10.1016/j.jpain.2014.08.014

63. Saccomanni B. Inflammation and shoulder pain-a perspective on rotator cuff disease, adhesive capsulitis, and osteoarthritis: conservative treatment. Clin Rheumatol. 2009;28(5):495-500.

64. Basbaum AI, Bautista DM, Scherrer G, Julius D. Cellular and molecular mechanisms of pain. Cell. 2009;139(2):267-284. doi:10.1016/j. cell.2009.09.028

65. Bunker TD, Reilly J, Baird KS, Hamblen DL. Expression of growth factors, cytokines and matrix metalloproteinases in frozen shoulder. J Bone Joint Surg Br. 2000;82(5):768-773.

66. Liu D, Song J, Ji X, Liu Z, Cong M, Hu B. Association of genetic polymorphisms on VEGFA and VEGFR2 with risk of coronary heart disease. Medicine. 2016;95(19):e3413. doi:10.1097/ MD.0000000000004864

67. Xu Y, Murrell GA. The basic science of tendinopathy. Clin Orthop Relat Res. 2008;466(7):1528-1538. 


\section{Supplementary material}

Table SI Differences in radiotherapy fields and chemotherapy regimens between participants in the no-low and moderate to high shoulder pain categories

\begin{tabular}{|c|c|c|c|c|}
\hline Characteristic & No - Low Pain $(n=\mid 84)$ & Moderate - High Pain $(n=60)$ & $P$-value & Test \\
\hline Radiotherapy field & & & 0.292 & $\chi^{2}$ \\
\hline None & $33.1(56)$ & $24.6(14)$ & & \\
\hline $\mathrm{CW}$ & I8.3 (3I) & $12.3(7)$ & & \\
\hline$C W+S / C$ & $27.8(47)$ & $36.8(2 I)$ & & \\
\hline $\mathrm{BCT}$ & $18.9(32)$ & $21.1(12)$ & & \\
\hline$B C T+S / C$ & $1.8(3)$ & $5.3(3)$ & & \\
\hline Chemotherapy regimen & & & 0.259 & $\chi^{2}$ \\
\hline None & $26.7(43)$ & $16.7(9)$ & & \\
\hline $\mathrm{AC}$ & $5.0(8)$ & II.I (6) & & \\
\hline AC/Docetaxel & $1.2(2)$ & $3.7(2)$ & & \\
\hline CAF & $36.0(58)$ & $27.8(15)$ & & \\
\hline CAF/Carboplatin & $0.6(1)$ & $0.0(0)$ & & \\
\hline $\mathrm{CAF} / \mathrm{CMF}$ & $0.6(I)$ & $0.0(0)$ & & \\
\hline CAF/FEC & $1.2(2)$ & $0.0(0)$ & & \\
\hline CAF/FEC/Docetaxel & $0.6(I)$ & $0.0(0)$ & & \\
\hline $\mathrm{CAF} / \mathrm{TC}$ & $0.0(0)$ & $1.9(1)$ & & \\
\hline CMF & $7.5(12)$ & $5.6(3)$ & & \\
\hline CMF/Docetaxel & $0.6(1)$ & $0.0(0)$ & & \\
\hline EC & $3.7(6)$ & $9.3(5)$ & & \\
\hline FEC & $12.4(20)$ & $16.7(9)$ & & \\
\hline FEC/Docetaxel & $1.2(2)$ & $1.9(1)$ & & \\
\hline FEC/Paclitaxel & $2.5(4)$ & $3.7(2)$ & & \\
\hline Paclitaxel & $0.0(0)$ & $1.9(1)$ & & \\
\hline
\end{tabular}

Notes: Data presented as \% (n). $P$-values in bold typeset indicate statistical significance $(P<0.05)$.

Abbreviations: CW, Chest wall; S/C, Supraclavicular field; BCT, Breast; $\chi^{2}$, Chi-squared test; AC, Adriamycin-Cyclophosphamide; CAF, Cyclophosphamide-AdriamycinFluorouracil; CMF, Cyclophosphamide-Methotrexate-Fluorouracil; EC, Epirubicin-Cyclophosphamide; FEC, Fluorouracil-Epirubicin-Cyclophosphamide; TC, PaclitaxelCyclophosphamide. 
Table S2 Differences in radiotherapy fields and chemotherapy regimens between participants in the no-low and moderate to high shoulder disability categories

\begin{tabular}{|c|c|c|c|c|}
\hline Characteristic & No - Low Disability $(n=202)$ & Moderate - High Disability $(n=42)$ & $P$-value & Test \\
\hline Radiotherapy field & & & 0.841 & $\chi^{2}$ \\
\hline None & $30.9(58)$ & $31.6(12)$ & & \\
\hline $\mathrm{CW}$ & $17.6(33)$ & $13.2(5)$ & & \\
\hline$C W+S / C$ & $29.8(56)$ & $31.6(12)$ & & \\
\hline $\mathrm{BCT}$ & $19.7(37)$ & $18.4(7)$ & & \\
\hline $\mathrm{BCT}+\mathrm{S} / \mathrm{C}$ & $2.1(4)$ & $5.3(2)$ & & \\
\hline Chemotherapy regimen & & & 0.133 & $\chi^{2}$ \\
\hline None & $26.4(47)$ & $13.5(5)$ & & \\
\hline $\mathrm{AC}$ & $5.1(9)$ & $13.5(5)$ & & \\
\hline AC/Docetaxel & $1.2(2)$ & $5.4(2)$ & & \\
\hline CAF & $35.4(63)$ & $27.0(10)$ & & \\
\hline CAF/Carboplatin & $0.6(\mathrm{I})$ & $0.0(0)$ & & \\
\hline $\mathrm{CAF} / \mathrm{CMF}$ & $0.6(\mathrm{I})$ & $0.0(0)$ & & \\
\hline CAF/FEC & $1.2(2)$ & $5.4(2)$ & & \\
\hline CAF/FEC/Docetaxel & $0.6(1)$ & $0.0(0)$ & & \\
\hline $\mathrm{CAF} / \mathrm{TC}$ & $0.0(0)$ & $2.7(I)$ & & \\
\hline $\mathrm{CMF}$ & $6.7(12)$ & $8.1(3)$ & & \\
\hline CMF/Docetaxel & $0.6(I)$ & $0.0(0)$ & & \\
\hline EC & $4.5(8)$ & $8.1(3)$ & & \\
\hline FEC & $12.9(23)$ & $16.2(6)$ & & \\
\hline FEC/Docetaxel & I.I (2) & $2.7(1)$ & & \\
\hline FEC/Paclitaxel & $3.4(6)$ & $0.0(0)$ & & \\
\hline Paclitaxel & $0.0(0)$ & $2.7(I)$ & & \\
\hline
\end{tabular}

Notes: Data presented as \% (n). P-values in bold typeset indicate statistical significance $(P<0.05)$.

Abbreviations: CW, Chest wall; S/C, Supraclavicular field; BCT, Breast; $\chi^{2}$, Chi-squared test; AC, Adriamycin-Cyclophosphamide; CAF, Cyclophosphamide-AdriamycinFluorouracil; CMF, Cyclophosphamide-Methotrexate-Fluorouracil; EC, Epirubicin-Cyclophosphamide; FEC, Fluorouracil-Epirubicin-Cyclophosphamide; TC, PaclitaxelCyclophosphamide.

Table S3 A priori power calculation to determine adequacy of sample size

\begin{tabular}{|c|c|c|c|c|c|c|c|c|c|c|}
\hline \multirow[t]{3}{*}{ MAF } & \multirow[t]{3}{*}{ OR } & \multicolumn{9}{|c|}{$\mathbf{N}$ (number of participants with moderate - high pain/disability required for $\mathbf{8 0} \%$ power) } \\
\hline & & \multicolumn{3}{|c|}{ Dominant model } & \multicolumn{3}{|c|}{ Recessive model } & \multicolumn{3}{|c|}{ Log-additive model } \\
\hline & & Pain & Disability & AVE & Pain & Disability & AVE & Pain & Disability & AVE \\
\hline \multirow[t]{3}{*}{0.15} & 1.5 & 347 & 303 & 325 & 3026 & 2584 & 2805 & 270 & 233 & 252 \\
\hline & 2.0 & 118 & 102 & 110 & 1006 & 833 & 920 & 93 & 79 & 86 \\
\hline & 2.5 & 68 & 58 & 63 & 571 & 461 & 516 & 55 & 46 & 51 \\
\hline \multirow[t]{3}{*}{0.20} & 1.5 & 306 & 269 & 288 & 1739 & 1487 & 1613 & 218 & 189 & 204 \\
\hline & 2.0 & 105 & 92 & 99 & 579 & 481 & 530 & 76 & 65 & 7II \\
\hline & 2.5 & 60 & 53 & 57 & 329 & 267 & 298 & 45 & 38 & 42 \\
\hline \multirow[t]{3}{*}{0.30} & 1.5 & 289 & 257 & 273 & 823 & 707 & 765 & 169 & 148 & 159 \\
\hline & 2.0 & 100 & 89 & 95 & 275 & 231 & 253 & 60 & 52 & 56 \\
\hline & 2.5 & 58 & 52 & 55 & 157 & 129 & 143 & 36 & 30 & 33 \\
\hline \multirow[t]{3}{*}{0.40} & 1.5 & 319 & 288 & 304 & 507 & 439 & 473 & 150 & 132 & $|4|$ \\
\hline & 2.0 & 111 & 101 & 106 & $17 \mid$ & 145 & 158 & 53 & 47 & 50 \\
\hline & 2.5 & 64 & 59 & 62 & 98 & 82 & 90 & 32 & 28 & 30 \\
\hline \multirow[t]{3}{*}{0.50} & 1.5 & 399 & 362 & 381 & 369 & 322 & 346 & 146 & 130 & 138 \\
\hline & 2.0 & 139 & 129 & 134 & 125 & 108 & 117 & 52 & 46 & 49 \\
\hline & 2.5 & 81 & 76 & 79 & 72 & 61 & 67 & 31 & 27 & 29 \\
\hline
\end{tabular}

Notes: The number of unmatched participants in the no - low category per participant in the moderate - high category was 3 and 4 for pain and disability, respectively, based on the expected prevalence calculated from previous reports as described in the section on sample size.

Abbreviations: MAF, Minor Allele Frequency; OR, Odds Ratio; AVE, Average. 
Table S4 Post-hoc power calculation to determine statistical power

\begin{tabular}{|c|c|c|c|c|c|c|}
\hline \multirow[t]{3}{*}{ SNP } & \multirow[t]{3}{*}{ MAF } & \multirow[t]{3}{*}{ OR } & \multicolumn{4}{|c|}{ Power (\%) } \\
\hline & & & \multicolumn{2}{|c|}{ Shoulder Pain $\left(n^{a}=5 I\right)$} & \multicolumn{2}{|c|}{ Shoulder Disability $\left(n^{b}=37\right)$} \\
\hline & & & D & $\mathbf{A}$ & D & $\mathbf{A}$ \\
\hline \multirow{4}{*}{$\begin{array}{l}\text { KDR } \\
\text { rs7667298 }\end{array}$} & & & & & & \\
\hline & 0.52 & 1.5 & 58.7 & 96.4 & 58.0 & 96.4 \\
\hline & & 2.0 & 95.3 & 100 & 94.7 & 100 \\
\hline & & 2.5 & 99.7 & 100 & 99.6 & 100 \\
\hline \multirow[t]{3}{*}{ rs2305948 } & 0.13 & 1.5 & 66.3 & 76.1 & 66.9 & 77.0 \\
\hline & & 2.0 & 98.5 & 99.6 & 98.7 & 99.7 \\
\hline & & 2.5 & 100 & 100 & 100 & 100 \\
\hline \multirow{4}{*}{$\begin{array}{l}\text { MMP2 } \\
\text { rs708269 }\end{array}$} & & & & & & \\
\hline & 0.28 & 1.5 & 76.5 & 93.6 & 76.5 & 93.9 \\
\hline & & 2.0 & 99.5 & 100 & 99.5 & 100 \\
\hline & & 2.5 & 100 & 100 & 100 & 100 \\
\hline \multicolumn{7}{|l|}{ NOS3 } \\
\hline \multirow[t]{3}{*}{ rs I549758 } & 0.16 & 1.5 & 70.9 & 82.5 & 71.4 & 83.3 \\
\hline & & 2.0 & 99.1 & 99.9 & 99.2 & 99.9 \\
\hline & & 2.5 & 100 & 100 & 100 & 100 \\
\hline \multicolumn{7}{|l|}{ THBS2 } \\
\hline \multirow[t]{3}{*}{ rs9766678 } & 0.32 & 1.5 & 75.7 & 94.9 & 75.5 & 95.1 \\
\hline & & 2.0 & 99.4 & 100 & 99.4 & 100 \\
\hline & & 2.5 & 100 & 100 & 100 & 100 \\
\hline \multicolumn{7}{|l|}{ TIMP3 } \\
\hline \multirow[t]{3}{*}{ rs715572 } & 0.15 & 1.5 & 69.6 & 80.7 & 70.1 & 81.4 \\
\hline & & 2.0 & 99.0 & 99.8 & 99.1 & 99.9 \\
\hline & & 2.5 & 100 & 100 & 100 & 100 \\
\hline \multirow[t]{3}{*}{ rs5754312 } & 0.40 & 1.5 & 71.4 & 96.2 & 71.0 & 96.3 \\
\hline & & 2.0 & 98.9 & 100 & 98.8 & 100 \\
\hline & & 2.5 & 100 & 100 & 100 & 100 \\
\hline
\end{tabular}

Notes: The number of unmatched participants in the no - low category per participant in the moderate - high category was 3 and 4 for pain and disability, respectively, based on the observed prevalence rates.

Abbreviations: SNP, Single nucleotide polymorphism; MAF, Minor Allele Frequency; OR, Odds Ratio; D, Dominant genetic model; A, Log-Additive genetic model; $\mathrm{n}^{\mathrm{a}}$, number of participants with moderate - high pain; $n^{b}$, number of participants with moderate - high disability.

\section{Publish your work in this journal}

Cancer Management and Research is an international, peer-reviewed open access journal focusing on cancer research and the optimal use of preventative and integrated treatment interventions to achieve improved outcomes, enhanced survival and quality of life for the cancer patient.
The manuscript management system is completely online and includes a very quick and fair peer-review system, which is all easy to use. Visit http://www.dovepress.com/testimonials.php to read real quotes from published authors. 